\title{
Seize the opportunity
}

\author{
PARTHA KAR ${ }^{1}$, ROBERT GREGORY2
}

\section{Introduction}

We know what should be done, so why don't we do it?' ${ }^{1}$ There is no shortage of documents produced in the last 20 years addressing the essentials of good diabetes care. Despite this, the evidence demonstrates that the care experienced by too many people with diabetes falls short of the minimum standard expected. The latest National Diabetes Audit data for England and Wales shows that the rate of improvement in delivery of care processes and of achieving targets has slowed. ${ }^{2}$ The guidance aimed at commissioners and providers is not mandatory and has had limited impact.

There are many reasons for this - a lack of political will, a fractured diabetes leadership, vested interests and financial constraints have all been suggested, as well as resistance to innovation and a variable appetite for sharing and implementing best practice. There is general agreement that the Quality and Outcomes Framework has delivered what it can for diabetes, and other quality levers are needed to take performance to the next level.

Planning is difficult when the organisations commissioning services are themselves subject to re-organisation. One could argue that the latest top-down reorganisation of the NHS in England set back the cause of diabetes care. NHS Diabetes was dismantled; it became unacceptable to talk about diabetes - a single chronic disease except as a generic long-term condition. It has taken several years of sustained argument by organisations representing patients, carers and healthcare professionals to get diabetes seen correctly as a priority. Offering NHS contracts to any willing provider while excluding local specialists from commissioning discussions because they have conflicts of interest is another perverse consequence of how the legislation is being interpreted.

Although Scotland, Wales and Northern Ireland have been spared this particular upheaval, the NHS in these countries is facing the same financial crisis and a supply versus demand mismatch as the prevalence of type 2 diabetes in particular continues to rise. Each administration has produced a diabetes strategy and a modest amount of dedicated funding. ${ }^{3-5}$ The only game in town for the NHS in England

Consultant Diabetologist, Portsmouth Hospitals NHS Trust, Associate Clinical Director, Diabetes, NHS England, UK

2 Consultant Diabetologist, University Hospitals of Leicester NHS Trust, Chair of $A B C D$, UK

Address for correspondence: Dr Partha Kar Consultant Diabetologist, Diabetes Centre, Portsmouth Hospitals NHS Trust, Queen Alexandra Hospital Southwick Hill Road Cosham, PO6 3LY, UK

E-mail: drparthakar@gmail.com

Br J Diabetes 2016;16:48-49

http://dx.doi.org/10.15277/bjd.2016.074
Tips for diabetologists leading system re-design

- Influence across the whole system, not just the acute trust

- Judge services (and yourselves) on hard outcomes

- General medicine work should not be to the detriment of specialist diabetes work

- Expand role as educator to support primary care acquiring capacity and capability

- It's OK to stop doing things if they are not needed

- Patient involvement for peer support and service re-design

- Embrace technology to work across trust boundaries

- Take calculated risks, don't be afraid to fail

- You don't need permission to be radical

was articulated before the last general election in Simon Stevens's Five Year Forward View, which secured additional funding in return for a transformative change to the way we do things. ${ }^{6} \mathrm{At}$ its core is a fundamental push towards service re-design, acknowledging that the traditional model of primary care generalists referring to secondary care specialists for each disease is neither sustainable nor good care.

Delivering the vision requires action on several fronts - reducing demand by prevention, harnessing the purchasing power of the NHS through better procurement and working differently in partnership with stakeholders. ${ }^{7}$ The national Type 2 Diabetes Prevention Programme underway in England is the beacon project seeking to address spiralling demand. A national approach to procurement of diabetes technology including glucose monitoring and insulin pumps is attractive, providing patient choice is not overly-constrained. Re-designing services to be more effective and cost-effective is, however, not something that is best managed at a national level.

\section{The Time is Now}

Vanguard sites have been established as leaders in service re-design, but they are not pilot sites and the rest of us cannot afford to wait and see what happens before taking action. We do not need permission to be radical and innovative. So can the diabetes community as a whole take the opportunity on offer fundamentally to rethink how best to deliver care for people with diabetes in the populations we serve? Diabetologists must take the lead in this process, using their specialist knowledge and experience to engage with primary care colleagues, public health specialists, people with diabetes and their carers and the commissioners to decide what model of care is best for their population. The goal should be 'seamless care' - from diagnosis to the grave. This will be a challenging exercise, in which every element of what we do now will need to be justified if it is to be retained and patient experience placed firmly in the centre of discussions. One misconception will 
need to be addressed straight away. Diabetes specialist care is not the same as secondary care. The specialist skill set is not defined by where the individual works or who they are employed by. Diabetologists have specialist skills that are portable, and can be deployed in the community or in the primary care setting if that is what is felt to be in the best interests of the model of care. Their contribution will go beyond traditional face-to-face consultations if they adopt methods of working that are the norm in most industries e.g. email support to primary care teams, Skype consultations.

An essential part of service re-design is to examine what elements are best delivered by specialist teams. Most of these elements will be uncontroversial. Sub-specialty work requiring a multi-professional team - pregnancy, children and adolescents, acute foot problems, insulin pumps and advanced chronic kidney disease - is not something for which primary care has the skills or the capacity to deliver. Trusts have a responsibility for the $20 \%$ of adult inpatients with diabetes. How this can be achieved without specialist sessions for inpatient care beggars belief. To these we would add the management of type 1 diabetes, albeit not in the rigid traditional model, as experience of this condition is limited in most general practices, and even patients who are achieving their three treatment targets will value the opportunity to discuss aspects of their condition with the specialist team. Young people with type 1 diabetes are the hardest to engage with and have the worst outcomes for any group, a field ripe for innovation and sharing best practice. Peer support is underutilised in the NHS, but offers much in type 1 diabetes. Finally, there is a 'rag bag' of rare forms of diabetes, complex multi-morbidity and diabetes in hard-to-reach groups (care homes, prisons and mental health trusts) for whom specialist care will have a legitimate contribution to make.

Many diabetologists, especially but not exclusively those working in district general hospitals, make a disproportionately heavy contribution to general medicine as bed-holders and by serving the acute medical take. At such times they are not providing specialist care for people with diabetes. This needs to be taken into account when the whole system model of care for diabetes is agreed and costed, and the rationale explained to acute trust management. Patients and their carers expect prompt access to the right specialist when they are admitted to hospital with a diabetes-related problem, even if this is at a weekend. While we are not saying that diabetologists should not be practising general medicine (they are good at it!), this should not be to the detriment of diabetes specialist work.

Diabetes will feature in the sustainable transformation plans for all CCGs who will be held accountable for their results in the CCG Improvement and Assessment Framework from 2016-17. ${ }^{8}$ Although help will be available for outliers, we believe that dialogue between diabetologists and commissioners is the best way to avoid CCGs finding themselves on the naughty step. If it is proving difficult to arrange these crucial conversations, then $A B C D$ may be able to intercede, as may Diabetes UK through their local Clinical Champion.

For most, if not all, health economies it is possible to deliver care for all people with diabetes in a more effective and cost-effective way. To do this requires excellent clinical leadership, clear governance, respect for culture and relationships that already exist, service user and carer involvement at the centre, financial and contacting mechanisms that help rather than hinder innovation (even though there is unlikely to be any additional money), joined-up IT systems and a workforce that is committed to improvement and that understands its role. Consultant diabetologists have told us they are up for the challenge. The time has come to go and ruffle a few feathers, take some calculated risks and achieve something of which we can be proud.

\section{Conflict of interest None \\ Funding None}

\section{References}

1. Hillson R. We know what to do, so why aren't we doing it? Br J Diabetes Vasc Dis 2014;14:128-30. http://dx.doi.org/10.15277/bjdvd.2014.04

2. HSCIC, HQIP, Diabetes UK. National Diabetes Audit 2013-2014 and 2014-2015 Report. 1: Care Processes and Treatment Targets. http://www.hscic.gov.uk/catalogue/PUB19900/nati-diab-rep1-audi2013-15.pdf (accessed 2 June 2016)

3. Scottish Government. Diabetes Improvement Plan. http://www.diabetesinscotland.org.uk/Publications/Diabetes_Improvement_Plan_2014. pdf (accessed 2 June 2016)

4. Welsh Government. Together for Health - A Diabetes Delivery Plan http://gov.wales/docs/dhss/publications/130923diabetesen.pdf (accessed 2 June 2016)

5. Northern Ireland Government. Diabetes Strategic Framework https://www.health-ni.gov.uk/sites/default/files/consultations/dhssps/diabetes-strategic-framework-consultation-document.pdf (accessed 2 June 2016)

6. NHS. Five Year Forward View. https://www.england.nhs.uk/wpcontent/uploads/2014/10/5yfv-web.pdf (accessed 2 June 2016)

7. NHS. Five Year Forward View: Time to Deliver. https://www england.nhs.uk/wp-content/uploads/2015/06/5yfv-time-to-deliver-2506.pdf (accessed 2 June 2016)

8. NHS England. CCG Improvement and Assessment Framework 2016/17. https://www.england.nhs.uk/commissioning/wp-content/uploads/ sites/12/2016/03/ccg-iaf-mar16.pdf (accessed 2 June 2016)

\section{Dr Paul Grant is taking a leave of absence from his role as Editor-in-Chief of BJD. Dr Parth Narendran has kindly agreed to take over until Paul returns. Parth can be contacted on the usual email address editor@bjd-abcd.com}

